PNL.8176

UC-900

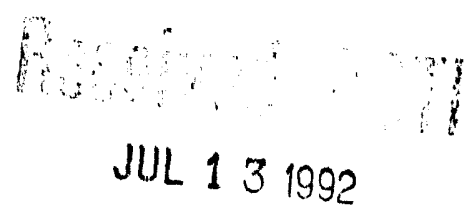

JUL 131992

\title{
Pacific Northwest Laboratory \\ Maintenance Implementation Plan
}

For Maintenance of

DOE Nuclear Facilities

J. D. Bright

June 1992

Prepared for the U.S. Department of Energy under Contract DE-AC06-76RLO 1830

Pacific Northwest Laboratory

Operated for the U.S. Department of Energy by Battelle Memorial Institute 


\title{
DISCLAIMER
}

This report was prepared as an account of work sponsored by an agency of the United States Government. Neither the United States Government nor any agency thereof, nor Battelle Memorial Institute, nor any of their employees, makes any warranty, expressed or implied, or assumes any legal liability or responsibility for the accuracy, completeness, or usefulness of any information, apparatus, product, or process disclosed, or represents that its use would not infringe privately owned rights. Reference herein to any specific cornmercial product, frocess, or service by trade name, trademark, manufacturer, or otherwise does not necessarily constitute or imply its endorsement, recommendation, or favoring by the United States Government or any agency thereof, or Battelle Memorial Institute. The views and opinions of authors expressed herein do not necessarily state or reflect those of the United States Government or any agency thereof.

\author{
PACIFIC NORTHWEST LABORATORY \\ operated by \\ BATTELLE MEMORIAL INSTITUTE \\ for the \\ UNITED STATES DEPARTMENT OF ENERGY \\ under Contract DE-AC06-76RLO 1830
}

Printed in the United States of America

Available to DOE and DOE contractors from the

Office of Scientific and Technical information, P.O. Box 62, Oak Ridge, TN 37031; prices available from (615) 576-840?. FTS 626.8401.

Available to the public from the National Technical Information Service,

U.S. Department of Commerce, 5285 Port Royal Rd., Springfield, VA 22161. 
PNL- -8176

DE92 016953

\section{PACIFIC NORTHWEST LABORATORY \\ MAINTENANCE IMPLEMENTATION PLAN}

For Maintenance of DOE Nuclear Facilities

June 15, 1992

MATERIALS DEVELOPMENT LABORATORY (306W Building)

WASTE TECHNOLOGY ENGINEERING LABORATORY (324 Building)

APPLIED CHEMISTRY LABORATORY (325 Building)

POST-IRRADIATION TEST LABORATORY (327 Building)

NEUTRON MULTIPLIER FACILITY (NMF) located within the CHEMICAL SCIENCES LABORATORY (329 Building)

Approved for Use and Application by:
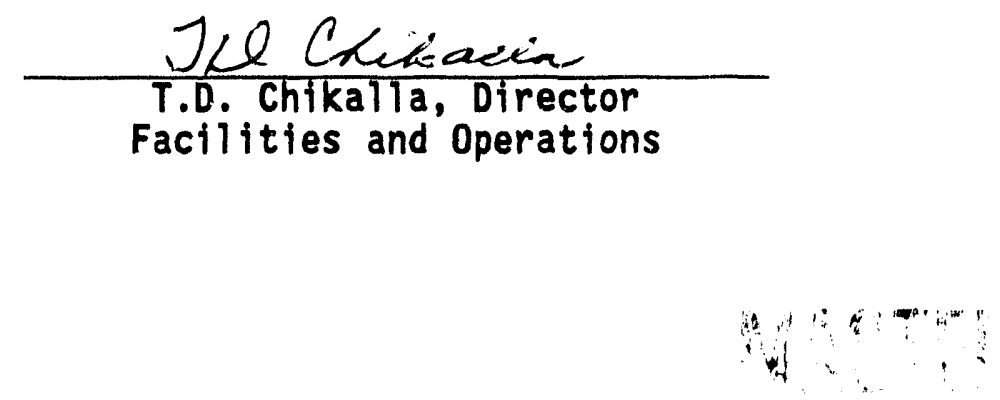
TABLE OF CONTENTS

1.0 Executive Summary $\ldots \ldots \ldots \ldots \ldots \ldots \ldots \ldots \ldots \ldots \ldots$

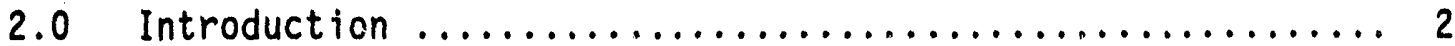

2.1 Facility Description $\ldots \ldots \ldots \ldots \ldots \ldots \ldots \ldots \ldots \ldots$

2.2 Mission $\ldots \ldots \ldots \ldots \ldots \ldots \ldots \ldots \ldots \ldots \ldots \ldots \ldots \ldots \ldots$

2.3 History/Scheduled Life ................... 8

3.0 DOE Order 4330.4A Requirements in addition to those stated

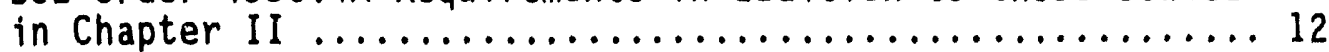

3.1 Identification of Structures, Systems and Compcnents included within the Maintenance Program .......... 12

3.2 Systematic Analysis describing Systems/Components included within the Preventive Maintenance Program, and determination of frequency of maintenance

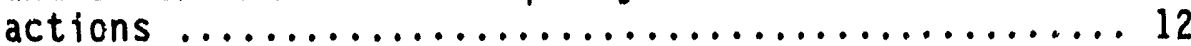

3.3 Self Assessment Program to Monitor the Maintenance Program ................................ 12

3.4 Graded Approach Strategy ...................... 13

3.4.1 Overall Strategy and Basis $\ldots \ldots \ldots \ldots \ldots 13$

3.4.2 Strategy for Safety-Related Items ........13

4.0 DOE Order $4330.4 A$ Chapter II Requirements ............. 14

4.1 Maintenance Organization and Administration........ 14

4.2 Training and Qualification of Maintenance Personnel.. 15

4.3 Maintenance Facilities, Equipment, and Tools ...... 17

4.4 Types of Maintenance $\ldots \ldots \ldots \ldots \ldots \ldots \ldots \ldots \ldots \ldots \ldots$

4.5 Maintenance Procedures .................... 20

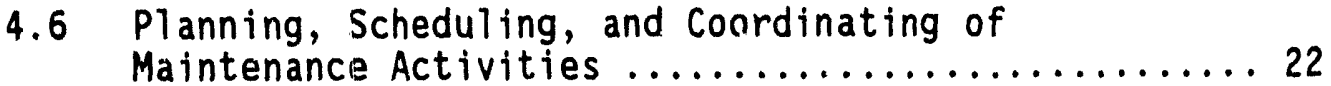

4.7 Control of Maintenance Activities ..............23

4.8 Post-Maintenance Testing ...................... 25 
4.9 Procurement of Parts, Materials, and Services .....26

4.10 Material Receipt, Inspection, Handling, Storage,

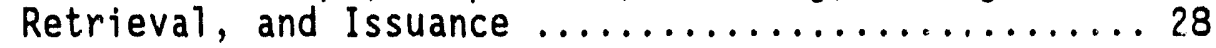

4.11 Control and Calibration of Measuring and Test

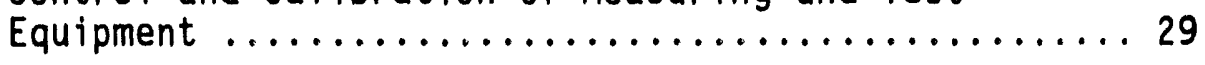

4.12 Maintenance Tools and Equipment Control ..........30

4.13 Facility Condition Inspection $\ldots \ldots \ldots \ldots \ldots \ldots$

4.14 Management Involvement $\ldots \ldots \ldots \ldots \ldots \ldots \ldots \ldots \ldots \ldots$

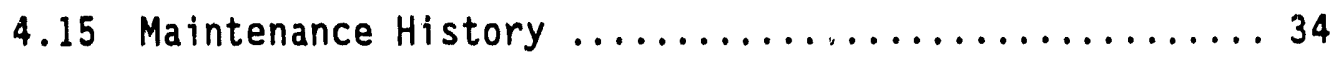

4.16 Analysis of Maintenance Problems ................. 35

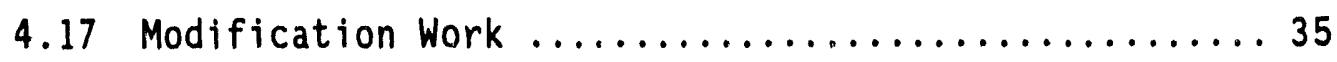

4.18 Additional Maintenance Management Requirements ..... 36

5.0 Deviations Requested with Supporting Rationale ......... 36

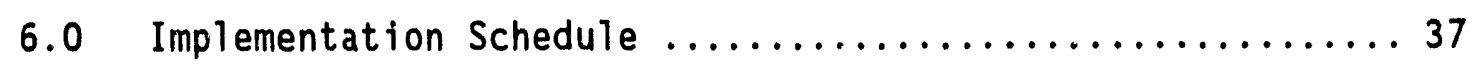

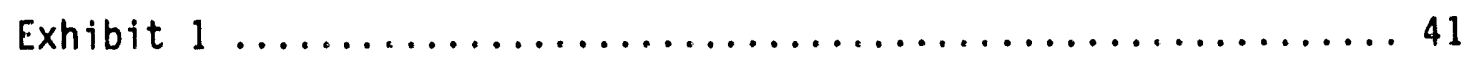

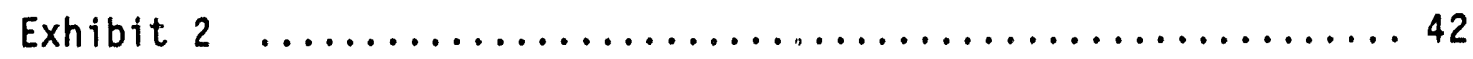




\subsection{EXECUTIVE SUMMARY}

This Maintenance Implementation plan has been developed for Pacific Northwest Laboratory's (PNL) Nuclear Facilities: 306W, 324, 325, 327 and 329NMF. It is based on a graded approach, self-assessment of the existing maintenance program(s) per the requirements specified by U.S. Department of Energy (DOE) Order 4330.4A, Chapter II, Change \#3. The results of this assessment were evaluated to determine needed improvements in PNL Craft Services' current maintenance program.

The objective of this implementation $\mathrm{plan}$ is to provide baseline information for compliance to the DOE $4330.4 \mathrm{~A}$, and for needed improvements. The prime consideration in applying a graded approach to the Order has been to maintain safe and reliable operations, environmental compliance, safeguards and security, programmatic mission, facility preservation, and/or other factlity-specific requirements.

Using the results of the self-assessment, PNL has selected nine of the 18 elements of the Maintenance Program defined by DOE Order 4330.4A for improvement. The elements selected for improvement are Training and Qualification of Maintenance Personnel; Maintenance Procedures; Planning, Scheduling, and Coordination of Maintenance; Control of Maintenance Activities; Post-Maintenance Testing; Facility Condition Inspection; Management Involvement; Maintenance History; and Additional Maintenance Requirements.

Based upon graded approach and current funding, those elements considered most important have been selected as goals for earliest compliance. Commitment dates for these elements have been established for compliance. The remaining elements of noncompliance will be targeted for implementation during later budget periods.

Section 3 of this $p l a n$ defines the structures, systems and components included within PNL's maintenance program; the method of determining frequency of maintenance actions; Facilities and Operations selfassessment program; and graded approach, including overall strategy and strategy for safety-related items.

Section 4 of this $p l a n$ lists the maintenance program elements required by Chapter II of DOE 4330.4A. The objective is taken directly from the Order. The discussion explains PNL's current practice and identifies al1 known areas that do not meet the intent of the order. The improvements section under each maintenance program element lists only those items, using the graded approach, currently planned for improvement.

Section 6 is the implementation schedule for those items, identified using the graded approach, currently planned for improvement. Action items reference the maintenance program elements contained in section 4. 


\subsection{INTRODUCTION}

This Maintenance Implementation Plan includes maintenance activities associated with the systems, structures and components located within the $306 \mathrm{~W}, 324,325,327$ and 329NMF complexes.

This plan will be reviewed regularly as incremental improvements have been completed. Appropriate modifications will be made to this plan, based upon regular self-assessments, as PNL moves toward full compliance with DOE 4330.4A. The Maintenance Implementation Plan (MIP) will be revised by June 30, 1994 unless a need is identified before that date. Budget information is not contained in this document. Maintenance budget information is contained in the PNL Site Maintenance PIan which will be submitted to RL annually, beginning September 30, 1992.

\subsection{Facility Descriptions}

\section{Materials Development Laboratory (306W Building)}

The Materials Development Laboratory is a two-story, bolted steel frame building with no basement located in the 300 Area of the Hanford Site. Building size is 36,500 square feet. Exterior siding is fluted steel-insulated panels. The concrete roof is 20 year built-up tar and gravel finish. The first floor is reinforced concrete while the second floor is steel deck topped with concrete. Laboratory and shop space are mostly unpartitioned and are roof or high bay height.

The building is equipped with metal working, heat treating, and finishing equipment. In this facility, pilot-phase fabrication processes are developed and demonstrated for full-scale production, and new materials concepts are refined and tested.

A complete machine shop provides shop services in support of development programs. The shop specializes in tool and die work, development and application of machining processes, and fabrication of specialized equipment.

Radiation monitoring is accomplished through the use of hand and shoe counters, radiation area monitors (RAMs), continuous air monitors (CAMs) and portable instrumentation.

Utilities (hot and cold water, propane, argon, hydrogen, steam and process sewer) are distributed throughout the laboratory. All water is filtered to remove sand and other impurities. The electrical system includes 440,208 , and $110 \mathrm{~V}(\mathrm{AC})$. Back-up electrical power is available for alarm systems and emergency lighting. Direct current for certain machines is supplied by motor generator sets or rectifiers as needed. Lighting is fluorescent with mercury vapor lamps in high-bays. There are three emergency alarm systems: fire gongs, evacuation sirens, and criticality horns. The building is fully sprinklered with a 3 - 
riser system. The building is served by four 2-ton cranes and two 1-ton cranes. Normal power is furnished by two 2500-kVA transformers, one on each side which can be switched back and forth to provide services to either side. The back-up transformer is rated at $30 \mathrm{kVA}$. Other standard safety features incorporated into the facility include fire extinguishers, safety showers, eyewash units, and hazardous material spill control kits.

\section{Waste Technology Engineering Laboratory (324 Building)}

The Waste Technology Engineering Laboratory is located in the 300 Area of the Hanford Site. The building size is 101,700 square feet. The 324 Building contains facilities for conducting diverse studies on the chemical and physical processing of high-level radioactive materials, physical and chemical characteristics of irradiated materials, and nonradioactive process development. The 324 Building contains laboratories, hot cells, support facilities, and office space to pursue technical studies that range from laboratory to pilot-plant scale. These studies involve the use of materials having levels of radioactivity from natural background to very high levels. In addition, laboratory research is performed to develop basic and applied data in support of DOE programs. The facility has been continually maintained so that the impacts of operations on the public, workers, and the environment are within acceptable limits and to ensure continuity of experimental programs.

The 324 Building was designed according to DOE criteria appropriate to a non-reactor nuclear facility. The major additions are not used for work with nuclear materials. The building is a metal-frame structure erected on reinforced concrete footings, basement walls, and floor slabs. The above-ground exterior shell is constructed of fluted steel panels, except for two portions that are concrete block masonry. The roof has a steel deck covered by insulated concrete and built-up tar and gravel. The building contains two groups of heavily shielded cells, their operating and service galleries, and two vaults for storing liquid radioactive materials. In addition, the building houses two engineering development laboratories and a high bay area used for nonradioactive process development activities. The hot cells are equipped with cranes, remote manipulator, viewing windows, various test equipment, process off-gas systems, and various services including air, water, and electrical. The hot cells and vaults are designed to shield the workers from direct radiation and, with the ventilation system and its high-efficiency particulate air (HEPA) filters, to confine any radioactive particulate materials. The basement contains laboratories and a Fissionable Materials Storage Vault. The structure and systems for the building were designed to the Uniform Building Code (UBC) and the Hanford Plant Standards (HPS) in existence at the time of their design, and therefore were designed to resist extreme weather and earthquake conditions. Entries to the building are 
above the level of the probable maximum flood (PMF). Design features offer protection against fires, criticalities, and other potential hazards. In general, several successive barriers to the release of radioactive or toxic materials are employed, with the exterior metal and masonry walls constituting a final barrier before release to the environment.

Utility services include steam; hot, cold, deionized, and distilled water; compressed air; propane and nitrogen; spare gases; process sewer (PS); retention process sewer (RPS); radioactive liquid waste system (RLWS); and normal building electrical services.

Radiation monitoring is accomplished through the use of hand and shoe counters, radiation area monitors (RAMs), continuous air molitors (CAMs), and portable instrumentation. Stack effluent monitoring consists of filter samples that are subject to radiological analysis. Backup electrical power is available, and fire sprinklers are provided. There are three emergency alarm systems: fire gongs, evacuation sirens, and criticality horns. Building power transformers are rated at $2000 \mathrm{kVA}$ at the High Bay Addition and 1680 kVA at the original building. The back-up transformer is rated at $225 \mathrm{kVA}$. The back-up transformer provides power to the stack monitor, air sample pumps, criticality alarm, fire protection system, backup process air compressor, PNL diverter system, supply. and exhaust fans and controls. Other standard safety features incorporated into the facility include fire extinguishers, safeiy showers, eyewash units, and hazardous material spill control kits.

\section{Applied Chemistry Laboratory (325 Building)}

The Applied Chemistry Laboratory is located in the 300 Area of the Hanford Site. The building size is 144,100 square feet. The building provides specially shielded, ventilated, and equipped laboratories for radiochemical analyses and nuclear process development studies. The facility has been maintained continually to ensure that operations can be conducted safely, with minimal potential impact on the public, workers, and the environment, and to ensure continuity of programmatic activities.

The building is a metal-frame structure erected on reinforced concrete footings, walls, and floor slabs. It contains offices, more than 50 laboratories with approximately 120 hoods and 40 gloveboxes, and 10 hot cells. The hot cells are designed to accommodate radiochemical processes with high radiation levels. They contain solvent-extraction pulse columns; an ion-exchange column; remote manipulators; viewing windows; other remotely operated equipment such as ovens, furnaces, and hoists; and offgas treatment, analytical chemistry, and dosimetry equipment. Similar but smaller-scale processes and equipment are also used with much smaller amounts of radiochemicals in the laboratories in 
the rest of the building. Research and development activities and equipment continually change as new DOE programmatic needs are identified, in keeping with the purpose of the facility.

The structural features of the hoods, gloveboxes, and cells are designed to provide a barrier to confine radioactivity, in conjunction with the ventilation system, which provides more negative air pressures in contaminated spaces and a system of redundant high-efficiency filters to remove any particulates before air is exhausted to the environment. The metal walls of the building provide another barrier to the escape of radioactive or toxic materials to the environment. This design, in conjunction with other design safety features, provides protection against the release of radioactive or toxic materials as a result of natural phenomena, fires or explosions, criticalities, and other potential accidents.

Utility services include steam; hot, cold, deionized, and distilled water; compressed air; propane and nitrogen; spare gases; process sewer (PS); retention process sewer (RPS); radioactive 1 iquid waste system (RLWS); and normal building electrical services.

Radiation monitoring is accomplished through the use of hand and shoe counters, radiation area monitors (RAMs), continuous air monitors (CAMs), and portable instrumentation. Stack effluent monitoring consists of filter samples that are subject to radiological analysis. Back-up electrical power is available, and isolated circuits for instruments, a 3000-1b electric elevator, and fire sprinklers are provided. There are three emergency alarm systems: fire gongs, evacuation sirens, and criticality horns. The normal transformer is rated at $1500 \mathrm{kVA}$, and the backup transformer at 1500 kVA. The back-up transformer provides power to the stack monitor, air sample pumps, criticality alarm, fire protection system, diverter systern, emergency air compressor, supply and exhaust fans and controls. Other standard safety features incorporated into the facility include fire extinguishers, safety showers, eyewash units, and hazardous material spill control kits.

\section{Post-Irradiation Test Laboratory (327 Building)}

The Post-Irradiation Test Laboratory is a single story building with a partial basement located in the 300 Area of the Hanford site. The size of the building is 26,900 square feet. The roof is a steel deck covered by a loosely laid ballasted membrane with a gravel finish. The exterior walls are fluted steel insulated panels. The first floor is reinforced concrete or steel decking with painted concrete. The building has 10,000 square feet of laboratory and work areas, 2,100 square feet of offices, and 2,400 square feet of storage areas ali.ig with 10,500 square feet of common areas containing ventilation and auxiliary equipment. 
The facility has a single pass ventilation system and is protected from fire by a wet pipe sprinkler system. Supply ventilation units are located in the basement; the west end of the high bay in the transfer (truck 10ck) and storage area; and the northwest storage area of the high bay. There are three emergency alarm systems; fire gongs, evacuation sirens, and criticality horns. The building is provided with continuous monitors for air activity, radiation, and criticality. The exhaust system takes air from all high-contamination areas such as shielded cells, fume hoods, dry storage, etc., and filters the air through a roughing filter, two high-efficiency particulate air (HEPA) filters, and lastly through an activated charcoal filter bank before the effluent air is released. The main electrical service to the facility is supplied by a 500 kVA transformer. Back-up electrical power is supplied by a 150 kVA transformer. Back-up electrical power is provided for exhaust fans, the radioactive liquid waste system (RLWS) pump, 6 radiation monitors and alarms, the public address system, the SERF cell, the cranes, the exit lights, and some emergency lights. Other standard safety features incorporated into the facility include fire extinguishers, safety showers, eyewash units, and hazardous material spill control kits. Radiation monitoring is accomplished through the use of personnel contamination monitors (PCM), hand and shoe counters, radiation area monitors (RAMs), continuous air monitors (CAMs), and portable instrumentation. Stack effluent monitoring consists of filter samples that are subject to radiological analysis. Another portion of the stack exhaust is continuously monitoren for the concentration of radiohalogen gases and particulates containing fission product activity and piutonium. This facility has four aqueous effluent systems that consist of the sanitary sewer (SS), process sewer (PS), retention process sewer (RPS) and RLWS. The SS serves only the change room, lunchroom, and office areas that have no potential for contamination.

Neutron Multiplier Facility (NMF) located within the Chemical Sciences Laboratory ( 329 Building)

The NMF is an attached annex near the southeast corner of the 329 Building. The 329 Building is located in the 300 Area of the Hanford Site. The NMF produces neutrons for activation analys is of organic and inorganic environmental samples. The NMF is a 26 foot by 20 foot by 16 foot high, one room structure made of insulated metal siding. The neutron multiplier device is installed in a 5 foot diameter by 20 foot deep water-filled pool. Access to this facility is monitored and controlled by a comprehensive security system. The NMF has its own separate HVAC system. The other components, systems and equipment that do not serve the NMF but are located within the 329 Building, are not considered a part of the nuclear facility. 
Radiation monitoring is accomplished through the use of hand and shoe counters, continuous air monitors (CAMs), and portable instrumentation. Other standard safety features incorporated into the facility include fire extinguishers, safety showers, eyewash units, and hazardous material spill control kits.

\subsection{Mission}

\section{Materials Development Laboratory (306W Building)}

The principal mission of the Materials Development Laboratory is materials sciences research. In the near term, this facility will continue as a laboratory facility focusing on materials development, fabrication engineering and mechanical metallurgy activities.

Waste Technology Engineering Laboratory (324 Building)

The principal mission of the Waste Technology Engineering Laboratory is chemical engineering development. The 324 Building provides hot cells, high bay laboratories, and technical office space for chemical engineering development focusing on waste treatment and large-scale process demonstrations.

\section{Applied Chemistry Laboratory (325 Building)}

The principal mission of the Applied Chemistry Laboratory is analytical and environmental chemistry and process/radiochemistry development. The 325 Building provides analytical chemistry laboratories, environmental chemistry laboratories, hot cells, and technical office space. Programmatic activities focus on waste management R\&D, analytical chemistry services, and radiochemical process development.

\section{Post-Irradiation Test Laboratory (327 Building)}

The principal mission of the Post-Irradiation Test Laboratory ( 327 Building) is post-irradiation examination and testing.

\section{Neutron Multiplier Facility (NMF) located within the Chemical} Sciences Laboratory (329 Building)

The Neutron Multiplier Facility (NMF) uses a multiplier ${ }^{252} \mathrm{Cf}$ assembly to produce neutrons for activation analys is of organic and inorganic environmental samples to produce radioisotopes for use in the radiochemical laboratories, and to produce short-lived radioisotopes for use as standards. The NMF annex to the 329 Building provides close proximity to related counting equipment, so delay between sample irradiation and counting is minimized. 


\subsection{History/Scheduled Life}

\section{Materials Development Laboratory (306W Building)}

The Materials Development Laboratory (306W Building) was originally built in two phases with various internal modifications and a two-story office addition subsequently added to it. The two-story office addition was added to the southwest corner of the building in 1981. Approximately 2400 gross square feet of area was added resulting in adding 12 additional offices plus a $20 \mathrm{ft}$ by $20 \mathrm{ft}$ conference room to the building.

In 1979 significant modifications we;e al so made to the north bay of the building including rooms 160, 161, 162, 163, and 164. They consisted of interior modifications, addition of double HEPA filter capability and the addition of redundant exhaust fans. In 1981 the remainder of the high bay was upgraded hy adding heat recovery systems, refrigerated air conditioning and double HEPAfiltered exhaust systems. A process water recirculation cooling system was added in 1992 to reduce cooling water discharge to the process sewer.

In the near term, this facility will continue as a "aboratory facility focusing on materials development, fabrication engineering and mechanical metallurgy activities. Long-term planning (responding to aging 300 Area infrastructure concerns) calls for constructing replacement space and closing this facility.

\section{Waste Technology Engineering Laboratory (324 Building)}

Major construction of the Waste Technology Engineering Laboratory (324 Building) was completed in 1965 in the 300 Area of the Hanford Site. It contains facilities for conducting diverse studies on the chemical and physical processing of high-level radioactive materials, physical and chemical characteristics of irradiated materials, and nonradioactive process developmerit. The original building was divided into five integrated but separate primary working areas:

- Area \#1--Engineering Development Laboratories (EDL-101 and EDL 102), tank pit, service tunnel, office area, and storage.

In 1974, a small addition, the lithium storage (324C) was constructed adjoining the southwest corner of EDL-101.

- Area \#2--First-floor ofrices, lobby, lunch room, conference room, men's restroom/change room, women's restroom/change room, decontamination rooin, janitor's closet, copy machine vestibule, telephone equipment room, second-floor offices. 
- Area \#3--Basement. Radiochemical Engineering (RE) cell service gallery, elevator equipment room, storage, and elevator vestibule; first floor-offices, restroom, firstfloor laboratory; second floor--laboratories, vestibule, restrooms; third floor--offices, chemical make-up rooms, head tank room, Zone III exhaust fan and filter rooms, RE cells control room; and the first-, second-, and third-floor RE cells and operating galleries. The RE cell complex consists of $A, B, C, D$, and Airlock cells.

- Area \#4--Storage vault and laboratory area, basement laboratories, mechanical spaces, Shielded Materials Facility (SMF) cells and operating galleries including offices, the manipulator repair shop, and the ventilation and equipment rooms. The SMF cell complex consist of East, South and Airlock cells.

- Area \#5--Zone I and Zone II exhaust fan and filter rooms, damper and filter pit, high-level vault, low-level vault, cask handling area, truck lock including the load out stall, high-and low-level vault sample room, low-level canyon, and the manipulator shop.

Attached to the building are several gas bottle storage areas, an acid storage tank, a scrubber for EDL exhaust, the building stack $(324 B)$, and the sampling building (324A) for the stack.

Since the original building was constructed, three major building areas have been added to the facility:

- Area \#6--In 1979, the High Bay Engineering Laboratory (HBEL) was added. It serves as a full-scale engineering development laboratory. It has an open area from floor to roof and three mezzanine levels that cover portions of the ground floor.

- Area \#7--In 1980, a Support Facilities Addition (craft shop) was constructed. It serves as the craft maintenance shop for the entire facility and contains two offices.

- Area \#8--In 1989, an office addition was constructed to house research and development staff. There are 24 offices, a conference room, and a women's restroom on the first floor, and 24 offices, a lunch room, and a conference room on the second floor.

The Radiochemical Engineering (RE) cells are being cleaned of equipment and materials from past programs. This program is scheduled to continue for several years to reduce the accumulation of radioactivity in these cells to the lowest levels practicable. All legacy equipment with no future programmatic use will be removed and the cells decontaminated. 
Major capital renovation projects will extend the useful life of the 324 Building for 25 years.

Applied Chemistry Laboratory (325 Building)

The Applied Chemistry Laboratory (325 Building) consists of a central portion completed in 1953 containing general purpose laboratories modified for low-level radiochemical work by provision of special ventilation and work enclosures; a front (south) wing containing office space, locker rooms, a lunch room and maintenance shops. An east wing was added in the late 1950s. A west wing was also added in the lare 1950s or early 1960s. These additions provide shielded enclosures with remote manipulators for high-level radiochemical work.

The filter addition area for the 325 building, completed in April 1978, provides a final testable HEFA filtration stage for ventilation exhaust air. Larger capacity exhaust fans were added for the higher system-pressure drop induced by the additional filter stage that tied into the existing 325 Building stack and dampers. Controls were added to ensure operation in concert with existing building power, ventilation supply, and exhaust requirements.

In 1978, A-Cell and C-Cell (east wing) were cleaned out, renovated, and re-equipped to process $50 \mathrm{Kg} / \mathrm{d}(1101 \mathrm{~b} / \mathrm{d})$ of 1 ight water reactor fuel as part of the Nuclear Waste Vitrification Project (NWVP). The project was shut down in 1980 , but no funds were provided for clean-up, so some unused equipment still remains. Space has been made in front of each cell window to conduct other research. Currently, that space is used for the tank sludge characterization program. B-Cell was not used during the NWVP program. It currently contains a core extruder and analytical measuring equipment used for the sludge characterization program.

Other modifications in the late 1980s upgraded the hallways, HVAC and common areas. These upgrades included new lighting fixtures along with replacing the ceiling tile, replacing all of the floor covering including the cove base and painting the walls.

In the near term this facility will continue as a laboratory performing multidisciplinary support focusing on waste management research and development, materials characterization, analytical chemistry services and radiochemical process development.

Major capital renovation projects will extend the useful life of the 325 Building for 25 years. 
Post-Irradiation Test Laboratory (327 Building)

The Post-Irradiation Testing Laboratory (327 Building) was built in 1950-1952 and initially commissioned for radioactive service in 1953. The facility has been and continues to be upgraded to meet changing emission and regulatory requirements. In addition, the 327 Building underwent major upgrading under a task force effort in support of the FFTF project. As part of an overall 300 Area upgrade, the RPS and RLWS systems were upgraded to improve operation and to further reduce potential for personnel exposure.

Other major modifications and additions were made to the facility from 1958 through 1970. These modifications added additional cell capabilities, transfer and storage rooms, and in 1966 an office addition was completed on the southwest corner. In 1970 the Special Environmental Radiometallurgy Facility (SERF) was added. SERF provides an examination and storage facility with a nitrogen atmosphere for specimens that may be affected by air. The SERF facility consists of an upper operating area and a lower storage area.

An operations business plan summarizing both existing and new funding opportunities for the 327 Building indicates considerable need for the hot cells for the foreseeable future. In addition to continuing support for the space power programs and future processing of various experimental assemblies irradiated either in the FFTF or at Idaho Falls, there is a significant need to provide hot cell support to the Site-wide waste characterization work, particularly as it relates to the single-shell and double-shell tank program.

A major renovation of the 327 Building will be needed for longterm continued use.

Neutron Multiplier Facility (NMF) located within the Chemical Sciences Laboratory (329 Building)

The Neutron Multiplier Facility (NMF) is annexed to the southeast corner of the 329 Building. It was constructed and began operation in the late 1970 s.

The NMF is currently being used minimally, due to the lowered neutron flux that is a result of the decay of the ${ }^{252} \mathrm{Cf}\left(T_{1 / 2}=\right.$ $2.64 \mathrm{yr}$.$) The facility is currently undergoing a management$ review to determine the viability of recharging the Neutron Multiplier to its rated capacity of $100 \mathrm{mg}$ of ${ }^{252} \mathrm{Cf}$. When this review is completed, a business plan will be developed to outline the future plans for the facility. 


\subsection{DOE ORDER 4330.4A REQUIREMENTS}

3.1 Identification of Structures, Systems and Components included within the Maintenance Program

The Maintenance Program for the PNL Nuclear Facilities includes the structures, systems and components as defined in Section 2.1, Facility Descriptions of this plan. A "Graded Approach" will be used to implement those elements of the Order with which PNL is not currently in full compliance.

3.2 Systematic Analysis describing systems/components included within the Preventive Maintenance Program, and determination of frequency of maintenance actions

System/component maintenance requirements are established based on analysis which considers safety classifications and risk assessments of facility, system, and component as well as technical specifications, standards and code requirements, Safety Analysis Reports (SARs) and Operational Safety Requirements (OSRs). The Preventive Maintenance Specialist determines optimum safe operating cycles, in conjunction with the Preventive Haintenance Engineer, based upon evaluation of the criteria listed above.

\subsection{Self-Assessment Program}

The Facilities and Operations' Self-Assessment Program applies to programs, activities, operations, and facilities under the sponsorship or direction of DOE. This program emphasizes the effective analysis and use of existing assessment activities, supplemented by special assessments as needed.

This program requires Facility and Operations managers to perform formal periodic reviews of their work activities and to identify successes and opportunities for improvement. The self-assessment program accomplishes this in an efficient manner by establishing a framework for the collection, analysis, and distribution of assessment data. One element of the self-assessment program is the process whereby managers continuously and candidly evaluate their organization's performance based on available information and commit to improvement actions as necessary. The formal selfassessment process focuses on compliance with DOE Orders and is formally documented. Improvement actions are also documented and tracked to completion.

Assessments will be augmented by periodic program surveillances by management and other responsible overview organizations. Results of all assessments and surveillances will be reviewed by appropriate levels of management, necessary corrective actions initiated, final assessment reports issued, alld changes to the Maintenance Implementation Plan made as necessary. 


\subsection{Graded Approach Strategy}

\subsubsection{Overall Strategy and Basis}

The PNL Maintenance "Graded Approach" is defined as the depth of detail required and the magnitude of resources expended for a particular maintenance management element. This is to be commensurate with the element's importance for safe and reliable operations, environmental

compliance, safeguards and security, programmatic mission, facility preservation, and/or other facility specific requirements.

\subsubsection{Strategy for Safety-Related Items}

PNL has initiated a graded approach based on a three tier risk based maintenance program as defined in the PNL Maintenance Program Risk Criteria (see Exhibit 1). PNL will develop a more integrated and uniform graded approach taking into consideration the requirements of other DOE Orders such as $5700.6 \mathrm{C}$ "Quality Assurance," 5480.19 "Conduct of Operations," 5480.20 "Personnel Selection, Qualification, Training, and Staffing" and 4320.2 "Capital Asset Management Process." Equipment on the master equipment list has been evaluated against the risk category criteria to determine its risk classification. The classifications is either High Risk, Medium Risk or Low Risk. These classifications will determine the depth of detail required and the magnitude of resources expended for a particular maintenance management element necessary for safe and reliable operations, environmental compliance, safeguards and security, programmatic mission, facility preservation, and/or other facility-specific requirements (see Exhibit 2 ).

The elements of the Order will also be implemented using a graded approach. This graded approach will be based on impact to safe and reliable operations, environmental compliance, safeguards and security, programmatic mission, facility preservation, and/or other facility-specific requirements. Work will be accomplished by effectively using the available resources and budgets to correct deficiencies prioritized by the graded approach.

Initially the aspects of the existing maintenance program will be enhanced in those areas identified by selfassessment as not adequate to the intent of the order. Once the program administrative controls and procedures are in place, attention will be directed to maintenance activities at the facility, system, and equipment level. Procedures delineating the guidance and responsibilities of the maintenance program that need to be revised have been identified. Emphasis will be placed on the completion of these revisions in order to ensure compliance with this plan. 


\subsection{DOE 4330.4A CHAPTER II REQUIREMENTS}

\subsection{Maintenance Crganization and Administracion}

Objective: The organization and administration of the maintenance function should ensure that a high level of performance in maintenance is achieved through effective implementation and control of maintenance activities.

Discussion: The maintenance organizational functions and responsibilities are defined in Craft Services Policies and Procedures (P\&PS) Manual. This manual is now being evaluated for compliance to DOE 4330.4A. The results of this Management Assessment will determine if any adjustment in the manual's contents will be necessary. Appropriate staff are currently assigned to maintain status quo of the maintenance program. However, additional staff may be needed to correct deficiencies and adjust for additional requirements contained in DOE $4330.4 \mathrm{~A}$.

Engineers are assigned to Craft Services (the maintenance organization) on an as-needed basis. In addition, there are a number of maintenance specialists assigned to the Preventive/Predictive Maintenance Group and the Compliance and Training Group. These engineers and specialists work jointly to support maintenance functions within Craft Services. Also, Craft Services receives additional support and assistance from the entire Facilities Engineering Section, when requested.

Craft Services stresses the importance of predictive maintenance and avoidance of costly breakdown repairs during off-shift, weekends, and holidays. Preventive Maintenance (PM) Checklist Standards are written to measure and predict degradation caused by the environment and time.

Facilities Engineering oversees contracted maintenance work to ensure it is performed to the same standard established for the maintenance organization. Facilities Engineering ensures contracted personnel are qualified for the work they perform.

Craft Services interfaces with the PNL Quality Programs Directorate and applies QA to the Maintenance Program through the PNL-MA-70 Manual and the QA P1an, CSD-1, Revision 2. Craft Services is in full compliance with the QA compliance criteria as detailed in CSD-1.

Craft Services has developed a very good working relationship with all organizations interfacing with the Maintenance Program. Authority, responsibility, and accountability for support organizations is defined in a series of PNL manuals. These manuals are defined and 1 isted in the PNL Management Guide, MG 1.0, Policies and Procedures System. 
Long-range planning is conducted in accordance with Craft Services P\&Ps, Section 7, Budgets and Cost Control. This section of the manual is in compliance with DOE guidelines for maintenance planning.

Maintenance personnel are held accountable for their performance through supervisory counseling as outlined in Craft Services P\&P 6.1.2, Appraisals--Bargaining Unit. Disciplinary actions are taken within the guidelines of the Management Gujde that address disciplinary action. Assigned tasks are being accomplished. Training has a heightened awareness, and time for required training classes has priority over work assignments.

Additional technical support may be required to meet the requirements of this order. Temporary increases in staffing requirements are generally met through the use of the on-site construction forces (Kaiser Engineers Hanford). All vacancies for permanent staff are filled with qualified individuals in a reasonable time frame. Long-range staffing plans are developed and submitted to senior management within the guidelines of Craft Services P\&Ps, Budgets and Cost Control.

Career progression $\mathrm{plans}$ are documented and tracked within the guidelines of Craft Services P\&Ps, Staff Development Reviews-Exempt; Staff Development Reviews--Nonexempt, Nonunit; and Appraisals--Bargaining Unit.

Improvements: No improvements are planned at this time.

\subsection{Training and Qualification of Maintenance Personnel}

Objective: A maintenance training and qualification program consistent with DOE 5480.5, Safety of Nuclear Facilities, DOE 5480.6, Safety of Department of Energy-Owned Nuclear Reactors, DOE 5480.18 , Accreditation of Performance Based Training For Category A Reactor and Nuciear Facilities, should be implemented to develop and maintain the knowledge and skills needed by maintenance personnel to effectively perform maintenance activities.

Discussion: Craft Services' training program is currently documented under Craft Services P\&PS, Section 14, Compliance and Training, and 19.1.1, Orientation and Safety Training Program. The procedure is now outdated due to drastic and extensive changes in PNL's approach to training and improvements in Craft Services training program. This section should be revised to comply with $4330.4 \mathrm{~A}$ and reflect current practice.

Craft Services training program encompasses all exempt staff, including management, and craft personnel. The training program is well understood through practice but is not documented. Craft Services provides continuing training to maintain and improve job related compliance knowledge and skills to all Craft Services 
personnel. This training is specifically designed within the guidelines of each individual's job assignments. Every craftsman receives an average of 75 hours of annual training. Exempt staff members receive training in line with their job assignments.

Each exempt position has a position description described in Craft Services P\&Ps, Section 4, Position Descriptions, which identifies job tasks, skill levels and responsibilities. Craftsmen position descriptions are described in the Bargaining Unit Agreement.

Training programs for each position are documented in the PNL Training Questionnaire for Craft Services, Facilities Services, and Power Operations staff members. The questionnaires are completed for each individual and reviewed by their supervisor.

The content and emphasis of the training is established in approved formal lesson plans for each required training class offered by PNL's Laboratory Training Center. Training schedules are offered and controlled by PNL's Laboratory Training Center. Craft Services prioritizes attendance of required classes over work schedules and other activities. Instructors/trainers are provided by the various training organizations within PNL. Craft Services will provide its own instructors/trainers when necessary. All instructors have received appropriate training.

All training classes coordinated by PNL's Training Center offer each student the opportunity to fill out class evaluation sheets. These cover the instructors knowledge and presentation of the class content, and any recommendations for improvements. Job-, craft- and crew-specific training is provided Craft Services personnel and by various research groups for their specific operations. PNL's Training Center offers multiple schedules of all listed classes. Craft Services works with the training center to schedule all individuals needing a particular class.

The formal OJT Program offered by Craft Services is the Apprenticeship Program. Craft Services employs fully-qualified journeyman craftsmen who have completed a certified apprenticeship, or equivalent, program. This program offers the opportunity for hands-on training conducted within the job environment. Craft Services' OJT Program is conducted within the stringent guidelines set down by the Joint Apprenticeship Committee as approved by the Washington State Department of Labor and Industries and Craft Services P\&P 15.1.0, Apprenticeship Program. OJT is overseen by journeymen crafts, who are selected for their expertise in their particular craft and the ability to instruct apprentices in developing their skills. Apprentices work alone only when considered qualified by line management to perform a specific job. Otherwise, apprentices function under the supervision of an experienced journeyman craftsman.

The Maintenance Training Program is approved and periodically reviewed by the Craft Services Manager. Each maintenance section 
manager also has input in the program's content and any proposed revisions. The programs are covered in Craft Services P\&Ps 15.1.0, Apprenticeship Program; and Section 14, Compliance and Training. Training programs are continually being improved to provide the best training available. Many improvements and changes are driven by frequently changing compliance criteria.

Improvement is needed to formalize Craft Services supervisor- and manager-specific training program.

Improvements: Both Craft Services P\&P, Section 14, Compliance and Training, and 19.1.1, Orientation and Safety Training Program, will be rewritten to reflect current practice by July $31,1992$.

Management and supervisor training will be developed, formalized, and incorporated into Craft Services P\&P Manual by July 31, 1992.

\subsection{Maintenance Facilities, Equipment, and Tools}

Objective: Maintenance facilities, equipment, and tools should efficiently support facility maintenance and maintenance training.

Discussion: Management and support staff for the PNL maintenance activities are located in the 350 Building Maintenance and operations facility. Also located in this facility are four individually supervised central shops consisting of electrical, machining, carpentry, sheetmetal, pipefitter, painter, welding and millwright crafts. PNL also has maintenance shops located in the $324,325,327,329$ Buildings and a machine shop in the $306 \mathrm{~W}$ Building. Both the 324 and 325 shops have supervisors located within the facility along with a captive maintenance crew. The 327,329 and $306 \mathrm{~W}$ shops have some captive craft support with supervision provided from the 350 Building. Additional craft support is provided from the 350 Building on an as-needed basis.

PNL Maintenance shops are provided with appropriate environmental controls and support equipment. Work benches and floor space are available to support normal work activities; additional shop space is available in the 350 Building Maintenance and Operations facility for activities requiring additional open floor space or enhanced capabilities. Where necessary exterior laydown areas are designated for material and/or equipment storage. Decontamination areas are provided by the operations groups. PNL does not use temporary facilities for maintenance activities.

Each shop contains storage (cabinets, shelves, etc.) and is available for equipment tools, and materials required to support normal work activities. This inventory of materials and supplies is controlled according to Craft Services Policy and Procedure 8.1.0, "Inventory and General Supplies." Additional controls are outiined within Policy and Procedures 8.1.1, "Bench Stock Level Control"; 8.1.2, "Inventory Control - Sensitive 
Material/Equipment"; 8.1.3, "Inventory Control and Procedure for Depleted Uranium"; 8.1.4, "Inventory Control, Movable Equipment"; 8.1.5, Small Tool Inventory and Accounting"; 8.1.8, "Security Spare Parts Inventory"; and 8.1.9, "Fire System Spare Parts Inventory." Environmental controls necessary for equipment and materials protection and personnel comfort are provided. Welding booths, parts cleaning areas, sand blasting equipment and machining areas are provided with appropriate ventilation equipment. Noise levels are monitored and craft personnel are trained through the PNL Hearing Conservation Program on methods to conserve hearing. Signs noting that hearing protection is required are also posted in facilities were necessary.

Office support equipment necessary to support the conduct of maintenance activities is available at the individual shops and in the Maintenance and Operations facility (350 Building). Necessary communications equipment is available for personnel to accomplish their assigned responsibilities.

Improvements: No improvements are planned at this time.

\subsection{Types of Maintenance}

Objective: A proper balance of corrective and preventive maintenance should be employed to provide a high degree of confidence that facility equipment degradation is identified and corrected, that equipment life is optimized, and that the maintenance program is cost-effective.

Discussion: A master list of equipment in the Preventive Maintenance (PM) Program exists, along with a listing of items submitted for inclusion into the program. Craft Services does an annual review of this listing to adjust frequency of inspections and eliminate equipment from the system, when appropriate.

Craft Services PM Program is documented in Craft Services P\&P 11.1.0, PM Program, which defines the performance parameters for its operation. This procedure should be expanded to comply with DOE 4330.4A. The PM Program includes equipment that affects safe and reliable facility operations. This equipment is assigned Safety Classifications which define safety importance and the degree of detailed maintenance to be provided. Equipment is assigned Safety Classifications by the interim procedure for implementation of the Safety Classification System.

A11 PM Checklist Standards are performed at predetermined scheduled intervals. These intervals are determined by utilizing vendor recommendations, engineering input, and equipment history. Al1 PM tasks and intervals are processed through Craft Services PM Specialist and must be approved by the various organizations who approve the PM Standard Checklists. PMs are documented on Craft Services PM Standard Checklists. These Checklists are filled out 
as the maintenance is performed by the craftsman in the field. Requested data is also filled in at the time of maintenance performance. A PM Waiver can only be approved by management.

Craft Services P\&P 11.1.0, PM Program, requires that all assigned PMs for a particular month be performed and returned to the PM Specialist by the third working day of the following month for review. This requirement is strictly applied in order for the PM Program to function as scheduled. Abnormalities are documented on the PM Standard Checkiist. Completed Checklists are reviewed by the assigned supervisor and PM Specialist for satisfactory completion of work and for any abnormalities which must be corrected. If the abnormality is safety-related, the craftsman has the responsibility to immediately report the condition to his/her supervisor and/or the Laboratory Safety Department.

The individuals performing the PM Standard Checklist in the field are journeymen craftsmen who are trained in their craft specialty to identify equipment and facility problems.

Facility equipment in the Craft Services PM Program is labeled to provide sufficient information. Equipment labeling is an ongoing process.

The Vibration Analysis Program is a computerized analysis program which plots vibration trends and predicts bearing failures.. From this data, bearings are replaced as a step per the routine PM before they fail. This procedure will be applied to other predictive maintenance techniques as they are developed. Vibration analysis routes, which gather vibration data for trending, are performed on a routine basis. Each piece of equipment is identified and probe sensing locations are marked on each piece of equipment so repeat monitoring results can be compared. For selected pieces of rotating equipment such as fans, pumps, etc., temperatures and speeds are recorded. Surveillance testing programs such as the Vibration Analysis Program produces a high degree of reliability at a substantial cost savings.

Performance of predictive maintenance is documented under craft Services P\&P 11.1.0, PM Program. Vibration analys is on rotating equipment and oil analysis are mainly used. These programs can determine failure modes, so that the PM can be performed before failure on a routine basis instead of as an emergency basis after failure. All parameters for the various predictive maintenance activities are determined and controlled in order to obtain comparable results. The Predictive Maintenance Program provides equipment history data.

Predictive maintenance is selectively applied to high and medium safety risk equipment/systems and where the most cost-effective results can be obtained. Craft Services P\&P 11.1.0, PM Program, documents the method and frequency of documenting Predictive 
Maintenance Program results so equipment failures can be avoided.

Corrective maintenance activities are controlled to ensure equipment and/or systems are returned to normal operating configuration. All corrective maintenance activities are controlled per Craft Services P\&P 9.2.0, Facilities Work Control Procedure. Good maintenance work practices are established and followed. Corrective maintenance activities ensure that the condition that caused the failure is identified, corrected, and documented.

The supervisor schedules daily maintenance activities based on experience and knowledge gained from past maintenance activities, and work request history file.

Craft Services has a work classification called "Do It Now" (DIN) work. Any work meeting this category is phoned in to the DIN Clerk who then dispatches craftsmen to perform the requested function. This function is for call-in jobs, urgent jobs, and/or other unforeseen events only.

Improvements: No improvements are planned at this time

\subsection{Maintenance Procedures}

Objective: Maintenance procedures and other work-related documents (e.g., drawings and instructions) should be prepared and used to provide appropriate work direction and to ensure that maintenance is performed safely and efficiently.

Discussion: Craft Services Policies and Procedures are general intent procedures, and are compiled in Craft Services P\&P Manual. The step-by-step procedures are Craft Services SMPs, CALs, and Welding Procedures. Each procedure bears a heading statement reading: STRICT COMPLIANCE TO POLICIES, PROCEDURES AND REQUIREMENTS IS MANDATORY. Compliance requirements are clearly stated in the procedures and communicated to each craftsman through reading assignments and training classes.

Craft Services preparation, review, approval, and revision of procedures is covered in Craft Services P\&P 17.1.0, Craft Services Procedures. This section covers all procedures but PM Standard Checklists, covered by Craft Services P\&P 11.1.0, PM Program.

Craft Services does not use documents in lieu of procedures, i.e., vendor manuals. Excerpts from vendor documents are commonly used in Craft Services SMPs, which do receive review and approval per Craft Services P\&P 17.1.0, Craft Services Procedures.

Procedures identified in Craft Services P\&P 17.1.0, Craft Services Procedures, are reviewed on set time periods depending on the type of procedure. 
Procedures and other work-related documents used in maintenance performance are considered technically accurate and maintained in a current state of accuracy. However, a working set of facility as-built drawings is not available.

Each crafis supervisor has a complete set of controlled procedure manuals in the work place; and these are available to the craftsmen at all times. The need for new procedures is determined by the maintenance work's impact and effect on safety and security items, plus the attention to detail required and degree of complication of the job.

Craft Services SMPs are not routinely validated; however, PM Standard Checklists are routinely validated during the Checklist's first use. This is covered in Craft Services P\&P 11.1.0, PM Program. Cautions, warnings, and hold points (such as quality checks) are included in the procedures, as needed.

Craft Services P\&Ps 11.1.0, PM Program, and 17.1.0, Craft Services Procedures, both serve as policy guidance documents and a writer's guide for procedures. Howeler, these procedures need to be revised to clarify and update Craft Services procedure writing practices. Temporary changes to procedures, when used, are controlled through appropriate review and authorization prior to use.

Each PM Standard Checklist has a remarks section set aside for field comments, which ain invited in order to improve the Checklists and PM Programs. A staff member can request, at any time, that a Craft Services procedure be reviewed for revision. This process is described in Craft Services P\&P 17.1.0, Craft Services Procedures.

The maintenance procedures program documents how procedures are tc be prepared, verified, validated, reviewed, approved, controlled, updated, revised, and used and specifies where these procedures are to be located. This is contained in Craft Services P\&Ps 17.1.0, Craft Services Procedures; and 11.1.0, PM Program.

A11 Craft Services P\&Ps are reviewed every two years for adequacy. They are revised whenever the need arises. Craft Services P\&Ps,

Section 4, Position Descriptions, and Section 17, Craft Services Procedure Control, are reviewed every two years.

Craft Services P\&P 16.1.0, Certified Vendor Information (CVI) Files, should be expanded to provide better detail of how Craft Services uses the filing system and what it can provide.

Improvements: Work with Design and Drafting Services Section and Facilities Management Department to develop a plan to improve 
status of as-built drawings by August $31,1993$.

Both Craft Services P\&Ps 11.1.0, PM Program, and 17.1.0, Craft Services Procedures will be revised. A procedure writer's guide will be developed and placed in the appropriate Craft Services P\&P Manual Section. P\&P 11.1.0 will be expanded to include procedure verification and validation by March 30, 1993.

Revise Craft Services P\&P 16.1.0, CVI Files, to provide better detail of how Craft Services uses the filing system and what it can provide by August 30, 1993.

\subsection{Planning, Scheduling, and Coordinating of Maintenance Activities}

Objective: An effective system for planning, scheduling, and coordinating maintenance activities should be implemented in order to ensure that maintenance is accomplished in a timely manner; improve maintenance efficiency; reduce radiation exposure (ALARA); and increase equipment availability.

Discussion: Craft Services elects to have supervisors plan maintenance activities and allocate manpower. Currently, crew sizes are too large to allow adequate supervision of work in progress. Craft Services needs to reduce the supervisor's span of control so that they can perform all assiyned duties. This will be addressed in a future revision of this plan. The estimating activity has never been formalized.

Craft Services controls planning and scheduling functions through Craft Services P\&Ps 10.1.0, Planning and Scheduling Policy; and 10.1.1, Planning and Scheduling Procedure. Work requests are tracked from the time they are issued to the field through final completion. P\&P 10.1.1 needs to be upgraded to incorporate the new Planning and Scheduling Computer Program, which has been installed.

Craft Services P\&P 9.2.0, Facility Work Control Procedure, describes the required work flow and required interfaces with all maintenance support organizations that are needed to complete maintenance activities. Pre-and post-job briefings are held for specific types of work such as confined space entry and radiation zone work. These briefings are required by PNL-MA-43, Industrial Hygiene, Occupational Safety, and Fire Protection Programs. Outages are controlled by use of the Management Guide, MG 9.5, Modification of Facilities and Utilities. All outages are coordinated with the various affected organizations. All outages are coordinated to obtain the maximum amount of work by all involved organizations in the available amount of time during the outage. Organizations involved in outages are given adequate time to make necessary arrangements and preparations for the work.

Backlog is monitored through the planning and scheduling process 
as outlined in Craft Services P\&P 10.1.1, Planning and Scheduling Procedure. Maintenance work requests are considered part of the backlog from the time the work is identified until all actions are addressed. This includes Post-Maintenance testing, as required, as outlined in Craft Services P\&P 9.2.0, Work Control Procedure. Control is maintained as outlined in Craft Services P\&P 10.1.1, Planning and Scheduling Procedure.

A work priority system is in place, used, and documented in Craft Services P\&P 10.1.1, Planning and Scheduling Procedure. The backlog is reduced on the basis of prioritization and facility safety significance. All Craft Services work is prioritized.

Supervisors hold weekly maintenance job scheduling meetings with building managers in order to complete work as scheduled and to coordinate work with other facility functions. The work schedules are documented.

Any outage schedule changes are immediately passed on to all affected parties who are designated to receive outage information. The length of an outage is determined by the job to be performed. other scheduled work for the facility is reviewed to determine if it would best be conducted during the same outage. Outages, outage schedules and coordination are maintained and scheduled by Facility Services. There has never been a problem with completing work elements and testing within the length of time designated for outages. Facility Services tracks completion of outage milestones.

Improvements: Craft Services P\&P 10.1.1, Planning and Scheduling, will be revised to reflect current practice and DOE $4330.4 \mathrm{~A}$ by May 31, 1993.

Craft Services P\&P 9.2.0, Facilities Work Control Procedure will be revised by May 31,1993 , to incorporate the new Planning and Scheduling Computer Program which will be installed.

The total amount of backlog is currently documented each year in the Long Range Work Plan. This information will be documented in the Site Maintenance Plan due September 30, 1992.

\subsection{Control of Maintenance Activities}

Objective: Management-directed and-delegated involvement in control of maintenance activities should ensure that maintenance practices are effective in maintaining safe and reliable facility operation.

Discussion: The Craft Services Work Request System is detailed in Craft Services P\&P 10.1.1, Planning and Scheduling Procedure. 
This procedure explains the processing of a work request, but needs to be expanded for more detail on the work request form itself and clarification of instruction on its use. The work request forms for Craft Services provide procedures and guidance for performing the work and allow for documentation.

All work requests are computer tracked from start to finish of work. This process is covered in Craft Services P\&P 10.1.1, Planning and Scheduling Procedure. This procedure should be revised to take into account the new Planning and Scheduling Computer Program.

Maintenance managers tour their facilities at every opportunity using walk-throughs, specific shop visits, or staff meetings in facility areas. Formal, documented inspections are conducted by all maintenance managers on a quarterly basis. Deficiencies are tracked to completion.

Maintenance performance is checked by observing people at work and a) so by inspecting, monitoring, and checking equipment and by timely follow-up of corrective actions. Craft Services supervisors are currently overburdened with administrative duties and cannot spend an adequate amount of time in the field to observe work in progress. This will be addressed in a future revision of this plan.

The Manager, Craft Services, receives copies of all assessment activities being performed within Craft Services. There is also a corrective actions log, which allows Craft Services management to monitor progress on all activities to ensure timely complation on all actions.

Line managers and supervisors are responsible for determining and implementing corrective actions, which are monitored by the QA and Compliance Specialist. Selected performance data, which exhibits negative trends and results, are forwarded to the appropriate levels of maragement for notification and input to corrective actions.

Changes to facility processes, alarms, etc., requires Facilities Engineering approval. This process is controlled by Management Guide 9.5, Modification of Facilities and Utilities; PNL-MA-90, Design: Preparation, Control, and Implementation; PNL-MA-595, QA Management PTan MP-F0-1, Revision 2; PNL-MA-598, PNL Configuration Management Plan for Facilities and Operations; and Craft Services P\&P 9.2.0, Facilities Work Control Procedure. Modification permits and associated work documents will identify any necessary spare parts and/or disposition of parts/materials reused. Documents affected by modifications such as drawings, etc., are the responsibility of Facilities Engineering to be as-built. The person responsible for affected procedures is responsible for their revisions. 
Temporary modifications are required to be approved by Facilities Engineering, and depending on the type of modification they will be reviewed and approved by the Laboratory Safety Department. This is covered by Craft Services P\&P 9.2.0, Facilities Work Control Procedure.

Completed modification permits are reviawed by members of the PM review committee to select equipment/systems which will require maintenance and incorporate them into the PM Program.

Work performed by vendors or construction forces is controlled by Facilities Engineering within the guidelines of PNL-MA-90, Design: Preparation, Control and Implementation and PNL-MA-91, Construction Project Management.

Craft Services does not use non-facility contractors and/or subcontractors to perform maintenance work. Facility Modifications are controlled by Facilities Engineering.

Improvements: Craft Services P\&P 10.1.1, Planning and Scheduling, will be revised to reflect current practice and DOE $4330.4 \mathrm{~A}$ by May $31,1993$.

\subsection{Post-Maintenance Testing}

Objective: Post-maintenance testing should be performed to verify that components will fulfill their design function when returned to service after maintenance.

Discussion: Craft Services conducts post-maintenance testing on selected pieces of equipment. The results are documented in the PM Standard Checklist for each specific piece of equipment. This program should be evaluated by the PM Program's administrator. A section should be added to Craft Services P\&P 11.1.0, PM Program, to explain how post-maintenance testing is conducted. Postmaintenance testing on corrective maintenance items are covered in Craft Services P\&P 9.2.0, Facilities Work Control Procedure. This procedure should also be reviewed for adequacy of post-maintenance testing.

The rigor of the testing depends on the equipment's Safety Classification Level and the significance of the facilities Operations Safety Requirements (OSR). All facility equipment have been reviewed for safety impact and classified with Safety Classification Levels.

Both Craft Services P\&Ps 11.1.0, PM Program, and 9.2.0, Facilities Work Control Procedure, should have a section added specifically dedicated to post-maintenance testing. Test requirements are identified by the Craft Services PM Specialist, with the test criteria being approved by all applicable organizations approving the specific PM Standard Checklist. The status of all PM Standard 
Checklists in the field for completion are tracked to ensure all items including post-maintenance testing are completed. All postmaintenance test results are reviewed by the PM Specialist who reviews all test data for acceptance to criteria and confirms that all appropriate sign-offs are on the documentation.

Usually post-maintenance tests are documented in an approved $\Gamma M$ Standard Checklist. The PM Standard Checklist gives instructions for maintenance and post-maintenance testing and identifies the documented data that is requested to be obtained. Postmaintenance testing is also performed on corrective maintenance when required by a Quality Control Record (QCR).

Test results are documented and reviewed by the craftsman/men and the responsible supervisor prior to returning the system/equipment back into service. Depending on the Safety Classification Level on the equipment/system, the Building Manager must al so confirm and sign acceptance for the system to be returned to operation. For tests which require participation of more than one organization, the assigned Craft Services supervisor is responsible for coordination of all appropriate personnel and actions to complete the test.

Rework is not well defined and identified in the work control system. The maintenance organization is not a formal participant in the acceptance test procedure (ATP) of modifications that have been contracted out.

Improvements: Evaluate PM Program for effectiveness, and adequacy of Post-Maintenance Testing Program to DOE 4330.4A requirements. Evaluation results will be incorporated into a revision of Craft Services P\&P 11.1.0, PM Program, which must also be revised to reflect current practice. Craft Services P\&P 9.2.0, Facility Work Control Procedure, will also be evaluated for adequacy and adjusted to meet compliance criteria. These actions will be completed by August $31,1993$.

The term rework will be defined for Craft Services application and a procedure developed for implementation and use by May 31, 1993.

Make arrangements for formal involvement in Acceptance Test Procedures (ATP) with Facilities Engineering by December 31, 1992.

\subsection{Procurement of Parts, Materials, and Services}

objective: Parts, materials, and services required for maintenance activities should be available when needed.

Discussion: All procurement activities at PNL are documented and controlled by PNL-MA-67, Procurement/Subcontracts User's Guide, and PNL-MA-70, Quality Assurance Manual, Section PAP-70-401, Purchase Requisitions. Procurement documents are reviewed for 
clarity, and for adequate technical and quality assurance requirements by Craft Services' QA Specialist, Material Coordinator and the PNL Purchasing Department. Documents not meeting these minimum requirements are returned to the originator.

Documented guidance is given for various items/equipment when engineering approvals are required for deviations from original design specifications. For facility equipment/parts, Facilities Engineering must approve any and all replacements or modifications from original specifications.

PNL-MA-67, Procurement/Subcontract User's Guide, contains provisions in the procurement procedures for emergency orders and emergency cash purchases, if the parts/materials can be located loca11y for quick purchase. Approximately $95 \%$ of all parts are ordered from catalogs from parts supply houses. The only requirement is that the parts ordered are a direct replacement part, or an engineering-approved substitute. There is no need to return to the original supplier, unless they are the only source for the parts.

Parts and material activities are reviewed annually. Adjustments in spare parts or material storage levels are made as a result of the annual 90 day inventories required by PNL-MA-69. Parts control could be improved by using a warehouseman. This will be addressed in a future revision of this plan.

Off-site services are used when the work is beyond the capabilities of plant forces in regard to time frame, skills, or equipment, in accordance with the Battelle HAMTC Bargaining Unit Agreement.

Electrical work must meet National Electrical Code requirements. Long lead-time items are identified and procured in advance of their need for maintenance work. Deficient or nonconforming items are placed in a locked area for physical control, and a Nonconformance Report issued in accordance with PNL-MA-70, Quality Assurance Manual, Section PAP-70-1501, Nonconformance Reports. Resolution of the problem is then negotiated with the supplier through the $Q A$ and Procurement Departments.

When requested and documented on the QCR Form for specific maintenance work, $Q A$ records are obtained, controlled and maintained for their intended purpose. This process is controlled by PNL-MA-70, Quality Assurance Manual, Section PAP-70-404, Obtaining Services.

Craft Services maintains an MSDS file for all hazardous materials and chemicals procured and used by Craft Services.

Improvements: No improvements are planned at this time. 
4.10 Material Receipt, Inspection, Handling, Storage, Retrieval, and Issuance

Objective: All phases of receiving, inspecting, handling, storing, retrieving, and issuing equipment, parts, and materials for maintenance should be covered by effectively implemented policies and procedures consistent with the Quality Assurance requirements of DOE 5700.6C, Quality Assurance, from the time an item is received until it is installed in the facility.

Discussion: Craft Services P\&Ps, Section 8.0, Materials Control, contains a series of procedures for controlling various types of materials and parts from receipt to installation. These procedures are also enhanced by the PNL-MA-70, Quality Assurance Manual's procedures PAP-70-1401, Inspection and Testing Status and Tagging; PAP-70-1301, Handling, Storage, and Shipping; PAP-701001, In-Process and Final Inspection; PAP-70-803, Item Identification and Control; PAP-70-706, Receiving Inspection; and PAP-70-401, Purchase Requisitions.

Currently, there are no items within Craft Services which require special handling; therefore, there are no applicable procedures/instructions. However, the QA Manual procedures remain a reminder that if an item does need special handling a procedure is required.

Materials are inspected to ensure conformance to requirements by the individual purchaser. In some cases, when warranted and/or required by compliance criteria, materials are inspected by a third party. These materials are accompanied by a Material Receiving Report, which is traceable to the applicable purchase order number.

Nonconforming items, such as suspect bolts, are tagged and locked up in designated areas until the item is returned to the vendor or the nonconformance is dispositioned. This process is controlled by PNL-MA-70, Quality Assurance Manual, Section PAP-70-1501, Nonconformance Reports.

Effective material procurement status and tracking of purchase orders is provided by PNL's Integrated Purchasing and Accounts Payable (IPAP) computerized purchasing program. All Craft Services purchases, except emergency cash purchases, are made by computer directly to the Purchasing Department. The status of an order can be obtained at any time.

No shelf-life control program is currently in place with Craft Services for facility material/parts. Craft Services is aware of the need for such programs; however, there are no currently stocked items which have shelf-life restrictions. If needed in the future, a shelf-life control program will be implemented. 
Safety-related items, when designated by the controlling organization (Safety, Security, Facilities Engineering, etc.), are segregated, maintained under lock and key conditions, and only issued for specific maintenance functions. Two programs currently in place are controlled by Craft Services P\&Ps 8.1.8, Security Spare Parts Inventory, and 8.1.9, Fire System Spare Parts Inventory.

Materials are stored within vendor provided guidance and/or industry guidance. Environmental and shelf-life controls are provided, if necessary. Currently, no materials are on hand which require either the environmental or shelf-life control systems. critical parts can be traced from purchase to installation, when requested, and be documented on the QCR Form.

Parts and materials are issued for use and are controlled, with unused materials returned to controlled storage areas when warranted by the job (e.g., a weld rod). Completed work documents will document material traceability when requested by the customer. Material receipt, inspection, handling, storage, retrieval, and issuance could be improved by utilization of a warehouseman. This will be addressed in a future revision of this plan.

Flammable and hazardous materials are identified, segregated, and properly controlled per PNL-MA-43, Industrial Hygiene, Occupational Safety, and Fire Protection Programs. PNL Craft Services complies with this manual.

Improvements: No improvements are planned at this time.

\subsection{Control and Calibration of Measuring and Test Equipment}

Objective: The program for control and calibration of measuring and test equipment (M\&TE) should be consistent with the Quality Assurance requirements of DOE 5700.6C, Quality Assurance, and ensure the accurate performance of facility instrumentation and equipment for testing, calibration, and repairs.

Discussion: All Craft Services M\&TE devices have unique numbers assigned to them by the Westinghouse Hanford Calibration Standards Laboratory when they are first calibrated. PNL contracts to Westinghouse for its calibration services.

Craft Services maintains a master listing of all M\&TE. This listing is kept current and provided to the PNL QA Department on an annual basis. Craft Services M\&TE items are calibrated with standards that are traceable to the National Institute of Standards and Technology.

Craft Services maintains the Craft Services Calibration (CAL) Manual which contains the policy for the Calibration Program and 
actual calibration procedures. This manual is in compliance with PNL-MA-70, QA Manua1, Section PAP-70-1201, Calibration Control System. Calibration frequencies are established for each piece of M\&TE within the guidance set down in Craft Services CAL Manual.

If a particular piece of M\&TE needs to be functionally checked before use, the calibration procedure describes the check to be performed. M\&TE is provided designated storage areas to control, issue and maintain its calibrated accuracies. Suspect or deficient M\&TE is segregated, tagged, and checked for accuracy. Equipment calibrated or checked with the suspect M\&TE is rechecked for accuracy. M\&TE that is designated a limited calibration receives a special colored calibration label which documents the instrument's limitations.

Craft Services has a computerized recall system for recalibration efforts, which also provides accountability and traceability of al1 calibrations made by any M\&TE. M\&TE found out of calibration or defective are inmediately tagged out of service, segregated from other M\&TE, and their accuracy checked to determine margins of error. Next, all instrumentation/equipment checked by the M\&TE is checked for accuracy. M\&TE reliability problems are trended to correct any negative trends. A maintenance/calibration history is maintained on all M\&TE.

The Craft Services M\&TE Program is routinely audited by the $Q A$ Department, and various other auditing organizations, in order to evaluate the effectiveness of the program.

Improvements: No improvements are planned at this time.

\subsection{Maintenance Tools and Equipment Control}

Objective: Methods should be established to provide for storage, issuance, and maintenance of an adequate and readily available supply of tools and equipment and also for the development of special tools and equipment needed in the maintenance program.

Discussion: Craft Services provides the tools, equipment, and supplies needed to support maintenance activities. Any special tools, recommended tools, equipment and supplies needed by craftsmen are purchased.

Tools and equipment are correctly stored and controlled within the guidelines of PNL-MA-69, Property Management. Special tools, jigs, and fixtures are identified and have designated storage areas. If proper loading, lifting, and transporting equipment is not available for a specific task, it will be obtained. When the tools/equipment design designates required maintenance, it is added to the PM Program for maintenance. Any defective or broken tools/equipment are immediately discarded or repaired. Only tools/equipment in good working order are available for use. 
The Site-wide Hanford Hoisting and Rigging Manual, WHC-CM-6-4, is required to be used by all Hanford Contractors. PNL is in fuTl compliance with this manual.

Scaffolding and rigging equipment is controlled by the Hanford Hoisting and Rigging Manual, and PNL-MA-43, Industrial Hygiene, Occupational Safety, and Fire Protection Programs. Craft Services is currently evaluating OSHA scaffolding criteria for additional compliance criteria.

Improvements: No improvements are planned at this time.

\subsection{Facility Condition Inspection}

Objective: Management should conduct periodic inspections of equipment and facilities to ensure excellent facility condition arid housekeeping.

Discussion: Craft Services P\&P 19.1.0, Housekeeping and Safety, covers Craft Services policy of facility conditions and required scheduled inspections for areas under Craft Services responsibilities (shop areas). Discrepancies are noted and tracked to completion; however, inspection checklists are generic rather than designed for each specific shop. Craft Services needs to revise P\&P 19.1.0 to add details for instruction on how the program functions.

A method for trending housekeeping deficiencies and facility assessment deficiencies needs to be developed and implemented.

Supervisors are required to inspect their assigned areas for housekeeping and safe practices at least monthiy. Section managers are required to inspect all work areas under the ir responsibility at least quarterly. This is covered in craft Services P\&P 19.1.0, Housekeeping and Safety. Supervisors are also responsible for checking craftsmen to ensure that maintenance work locations are left in a clean and orderly state.

Deficiencies found are entered into the Craft Services Work Control system for correction. Individuals are assigned direct responsibility for corrective actions and the deficiencies are tracked for completion.

Supervisors, specialists, and managers are trained in OSHA criteria inspections. Each participates in facility inspections.

Craft Services schedules periodic inspections and identifies areas to be inspected. Different individuals are routinely assigned to inspect the various shops. The results of craft Services shop and work area inspections are transmitted to the Laboratory Safety Department, and the Maintenance Manager. The Building Manager conducts inspections of his/her facilities on a regular basis. 
Significant conditions or safety deficiencies are cause to immediately stop any work or activity until conditions are returned to an acceptable condition. These conditions must also be reported within the guidance of PNL's Management Guide, ACT NOW Directive 90-7, Off-Normal Events.

Craft Services conducts condition assessment surveys through a comprehensive inspection program incorporated within the formal PM/Predictive Maintenance Program. In addition, concition assessment surveys are performed through the use of: Facility Upgrade Inspection Program, Roof Inspection Program, Interior and Exterior Paint Program, Energy Management, Cross Connection Program, and Facility Electrical Inspection Program.

The primary objective of the condition assessment survey program is the early detection of potential facility problems in order to prevent deterioration, possible damage to adjacent materiais or systems, and failure of comprivents.

PM Standard Checklists and Vibration Analysis Routes are standardized per Craft Services P\&P 11.1.0, PM Program, and are performed on a predetermined schedule. The individuals performing the PM Standard Checklist in the field are journeymen craftsmen who are trained in their craft specialty to identify equipment and facility problems. Facilities Upgrade Inspections are performed annually by a Technical Specialist and Building Manager.

Safety inspection reports are sent to the Laboratory Safety Department to document conditions and to assign corrective actions. Follow-up reports document completion of corrective actions. Shop inspections are covered by Craft Services P\&P 19.1.0, Housekeeping and Safety. This procedure needs to be revised to reflect current practice and to include a formal inspection checklist.

Craft Services schedules periodic inspections and identifies areas to be inspected. Different individuals are routinely assigned to inspect the various shops.

Craft Services' craftsmen (who are aided by PM specialists) routinely perform condition assessment surveys. During the investigation to resolve an identified problem area, consultants, engineers, or architects may be called in. The annual Facility Upgrade Inspection is conducted by a Technical Specialist and a Building Manager.

Improvements: Craft Services P\&P 19.1.0, Housekeeping and Safety, will be revised to reflect current practice by September 30, 1992 .

Inspection checklists designed for each specific shop area/equipment will be implemented by September 30, 1992 . 
A method for trending housekeeping deficiencies and facility assessment deficiencies will be implemented by June 30, 1993.

\subsection{Management Involvement}

Objective: To ensure the safety of DOE nuclear facility operations, DOE and contractor corporate and facility managers should be sufficiently involved with facility operations to be technically informed and personally familiar with conditions at the operating facility.

Discussion: Craft Services monitors the effectiveness and efficiency of the procurement and material control process on a continuous basis. In addition, the QA Department conducts an annual audit of the Craft Services QA PIan, which covers procurement and material control.

Craft Services continually reviews measuring and testing equipment to verify safe and reliable operation. This program also receives independent audits and surveys from the QA Department and DOE.

The maintenance training program is periodically reviewed to identify training program enhancements or changes in emphasis. This program is also extensively audited by third party organizations.

The PM Program backlog is reviewed monthly to verify that actions are effective in maintaining or reducing the backlog.

Craft Services tracks and evaluates repair cost of buildings measured in cost per square foot, amount of emergency maintenance cost, and backlog of maintenance and repair on a regular basis.

Various programs are integrated into the PM Program which monitor, collect, trend and analyze performance data. Examples of these are the Vibrations Analysis Program; $0 i 1$ Analys is Program; and Third Party Inspection Programs for pressure vessels, safety relief valves, and elevators. The results of the various monitoring programs are analyzed and the results used to determine equipment/system reliability.

Goals and parameters are established for all performance indicators, in order to monitor performance within acceptable limits and to measure success or failure of specific goals.

Maintenance managers tour their facilities at every opportunity using walk-throughs, specific shop visits, or staff meetings in facility areas. Formal documented inspections are conducted by all maintenance managers on a quarterly basis.

The Manager, Craft Services, receives copies of all assessment 
activities being performed within Craft Services. There is also a corrective actions log, which allows Craft Services management to monitor progress on all activities to ensure timely completion on al1 actions.

Line managers and supervisors are responsible for determining and implementing corrective actions, which are monitored by the $Q A$ and Compliance Specialist.

Selected performance data, which exhibits negative trends and results, are forwarded to the appropriate levels of management for notification and input to corrective actions. Root causes are determined for identified problems, and corrective actions tracked by Craft Services Action Item Log.

A management assessment self-appraisal to DOE-EH 0135, "Performance Objectives and Criteria for Technical Safety Appraisals at Department of Energy Facilities and Sites," was completed on August 30,1991. A schedule to perform selfassessments to DOE $4330.4 A$, Section 4.1, "Self-Assessments" has been established.

Adequate and effective feedback systems are currently in place in craft Services. These feedback systems include the open door policy, crafts safety committee, safety inspection walk-throughs performed by Craft Services management, safety inspections by the Laboratory Safety Department, and various audit/surveillance programs.

Craft Services does not have a formal work sampling program.

In-house "lessons learned" on maintenance experiences are obtained from the Craft Services In-house Surveillance Program, conducted by the Craft Services QA and Compliance Specialist. This individual also monitors and maintains the Craft Services audit log which tracks and trends all action items from the various audits/surveys, etc. The experience of others is obtained from the DOE $5000.3 \mathrm{~A}$ reporting program printouts.

Reports generated by the DOE $5000.3 \mathrm{~A}$ reporting program are reviewed periodically to determine trends, comparisons, and evaluate corrective actions taken to preclude similar situations at other DOE sites.

Improvements: Develop a work-sampling program and procedure by August 31, 1993.

\subsection{Maintenance History}

objective: A maintenance history and trending program should be maintained to document data, provide historical information for 
maintenance planning, and support maintenance and performance trending of facility systems and components.

Discussion: Craft Services collects maintenance history only on critical equipment which is contained in the PM Program. However, this program is not formalized or well documented. A new procedure should be established to cover equipment history.

Improvements: Develop a new procedure for equipment history that will comply with DOE $4330.4 \mathrm{~A}$ by August $30,1993$.

\subsection{Analysis of Maintenance Problems}

Objective: Systematic analysis should be used to determine and correct root causes of unplanned occurrences related to maintenance.

Discussion: In accordance with DOE 5000.3A Occurrence Reporting, Craft Services uses a systematic analysis methodology to determine and correct root causes of problems, unplanned events, and occurrences related to maintenance.

PNL uses DOE 5000.3A, Occurrence Reporting and Processing of Operations. Root causes are also determined in this reporting process. Corrective actions are tracked by the Facilities and Operations' Performance Assurance Department.

Diagnostic analysis will be performed to determine the scope of potential problems, if applicable, or to determine if a method of analysis is available for the particular application. Results of applied diagnostic analysis are used to determine options for corrective action. The analys is program addresses any generic corrective actions that need to be taken after problems with the specific piece of equipment have been determined and corrected.

Personnel performing diagnostic analys is are journeymen craftsmen, technical specialists and facilities engineers who have technical knowledge of the facility systems, equipment, and components. They al so have knowledge of materials used in construction and maintenance. Craftsmen are also supported by technical specialists to aid in technical concerns, problems, and to answer technical questions.

Improvements: No improvements are planned at this time.

\subsection{Modification Work}

Objective: Facility modification work, including temporary modifications, should be accomplished under the same basic administrative controls as those applied to facility maintenance activities so that there is no increase in risk to facility 
equipment, environment, or personnel because of the modification work.

Discussion: Temporary modifications are required to be approved by Facilities Engineering and, depending on the type of modification, they will be reviewed and approved by the Laboratory Safety Department. Temporary/emergency modifications are tracked through the Engineering Request (ER) system to ensure that a permanent repair/modification is obtained. This is delineated by Craft Services P\&P 9.2.0, Facilities Work Control Procedure.

Modification permits are reviewed by members of the PM review committee to select equipment/systems which will require maintenanc: and incorporate them into the PM Program.

Changes to building systems, alarms, etc., requires Facilities Engineering appro:al. This process is controlled by Craft Services P\&P 9.2.0, Facilities Work Control Procedure and PNL-MA90, Design: Preparation, Control and Implementation.

Documenis affected by modifications such as drawings, certified vendor information (CVI), etc., are the responsibility of

Facilities Engineering to be as-built. The person responsible for affected procedures is responsible for their revisions.

Work performed by vendors or construction forces is controlled by Facilities Engineering within the guidelines of PNL-MA-90, Design: Preparation, Control and Implementation and PNL-MA-9l, Construction Project Management.

Improvements: No improvements are planned at this time.

\subsection{Additional Maintenance Management Requirements}

Objective: A program should be in place to prevent equipment and building damage due to cold weather at any nuclear facility that may be at risk.

Discussion: The PM Program has a winterization program aspect that ensures equipment/systems are ready for winter conditions, and which allows for winter time-frame monitoring activities. There is also a spring/summer program to ensure that all airconditioning equipment, etc., is ready for use.

Improvements: A procedure for a formal freeze protection program will be developed and implemented by June 30, 1992.

\subsection{DEVIATIONS REQUESTED WITH SUPPORTING RATIONALE - (IF APPLICABLE)}

No deviations are requested. 


\subsection{IMPLEMENTATIONS SCHEDULE}

Reference section 4.2, Training and Qualification of Maintenance Personnel:

- Action: Both Craft Services P\&P, Section 14, Compliance and Training; and 19.1.1, Orientation and Safety Training Program, will be rewritten to reflect current practice.

Commitment Date: July 31, 1992

Responsible Individual: RE Hawks

- Action: Management and supervisor training will be developed, formalized, and incorporated into the Craft Services P\&P Manual.

Commitment Date: July 31, 1992

Responsible Individual: RE Hawks

Reference section 4.5, Maintenance Procedures:

- Action: Work with Design and Drafting Services Section and Facilities Management Department to develop a plan to improve status of as-built drawings.

Commitment Date: August 31, 1993

Responsible Individual: CC Wentz

- Action: Both Craft Services P\&Ps 11.1.0, PM Program, and 17.1.0, Craft Services Procedures will be revised. A procedure writer's guide will be developed and placed in the appropriate Craft Services P\&P Manual Section. P\&P 11.1.0 will be expanded to include procedure verification and validation.

Commitment Date: March 30, 1993

Responsible Individual: CC Wentz

- Action: Craft Services P\&P 16.1.0, CVI Files will be revised to provide better detail of how Craft Services uses the filing system and what it can provide.

Commitment Date: August 30, 1993

Responsible Individual: CC Wentz

Reference section 4.6, Planning, Scheduling, and Coordination of Maintenance: 
- Action: Craft Services P\&P 10.1.1, Planning and Scheduling, will be revised to reflect current practice and DOE 4330.4A (also referenced in section 4.7 ).

Commitment Date: May 31, 1993

Responsible Individual: CC Wentz

- Action: Craft Services P\&P 9.2.0, Facilities Work Control Procedure will be revised to take into account the new Planning and Scheduling Computer Program which has been installed.

Commitment Date: May 31, 1993

Responsible Individual: CC Wentz

- Action: The total amount of backlog is currently documented each year in the Long Range Work Plan. This information will be documented in the site Maintenance Plan due September 30, 1992.

Commitment Date: September 30, 1992

Responsible Individual: JD Bright

Reference section 4.7, Control of Maintenance Activities:

- Action: Craft Services P\&P 10.1.1, Planning and Scheduling, will be revised to reflect current practice and DOE $4330.4 \mathrm{~A}$ (a) so referenced in section 4.6).

Commitment Date: May 31, 1993

Responsible Individual: CC Wentz

Reference section 4.8, Post-Maintenance Testing:

- Action: Evaluate PM Program for effectiveness and adequacy of Post-Maintenance Testing Program to DOE $4330.4 \mathrm{~A}$ requirements. Evaluation results will be incorporated into a revision of Craft Services P\&P 11.1.0, PM Program, which must also be revised to reflect current practice. Craft Services P\&P 9.2.0, Facility Work Control Procedure, will also be evaluated for adequacy and adjusted to meet compliance criteria.

Commitment Date: August 31, 1993

Responsible Individuals: CC Wentz, RE Hawks

- Action: The term "rework" will be defined for Craft Services application and a procedure developed for implementation.

Commitment Date: May 31, 1993 
Responsible Individual: DD Hatley

- Action: Make arrangements for formal involvement in acceptance test procedures (ATP) with Facilities Engineering.

Commitment Date: December 31, 1992

Responsible Individual: DD Hatley

Reference section 4.13, Facility Condition Inspection:

- Action: Craft Services P\&P 19.1.0, Housekeeping and Safety, will be revised to reflect current practice.

Commitment Date: September 30, 1992

Responsible Individual: RE Hawks

- Action: Inspection checklists designed for each specific shop area/equipment will be implemented.

Commitment Date: September 30, 1992

Responsible Individual: RE Hawks

- Action: A method for trending housekeeping deficiencies and facility assessment deficiencies will be implemented.

Commitment Date: June 30, 1993

Responsible Individual: RE Hawks

Reference section 4.14, Management Involvement:

- Action: Develop a work-sampling program and procedure.

Commitment Date: August 31, 1993

Responsible Individuals: RE Hawks, JD Bright

Reference section 4.15, Maintenance History:

- Action: Develop a new procedure for equipment history that will comply with DOE $4330.4 \mathrm{~A}$.

Commitment Date: August 30, 1993

Responsible Individual: CC Wentz 
Reference section 4.18, Additional Maintenance Management Requirements:

- Action: A procedure for a formal freeze protection program will be developed and implemented.

Commitment Date: June 30, 1992

Responsible Individual: CC Wentz 


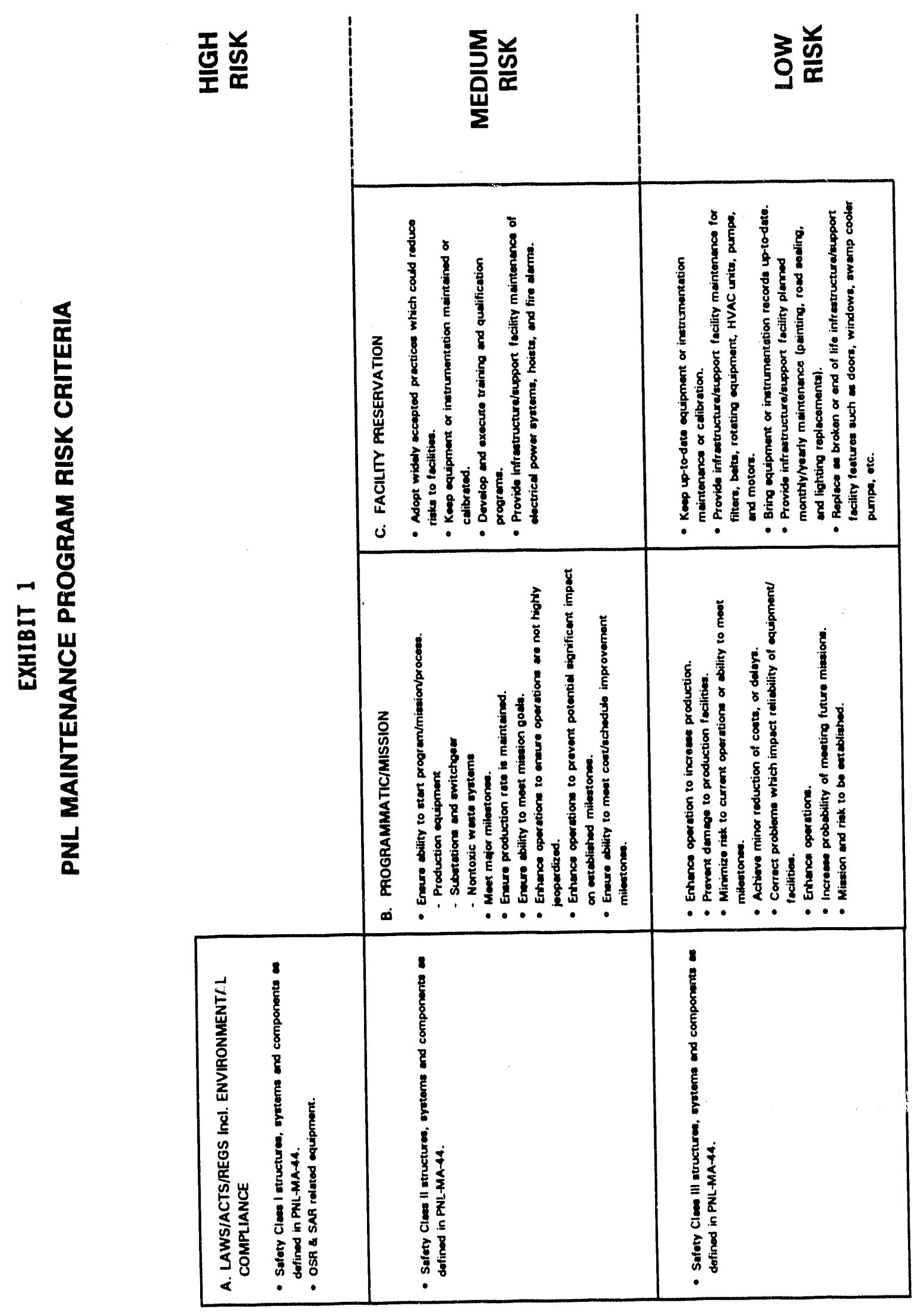




\begin{tabular}{|c|c|c|c|c|}
\hline \multirow{7}{*}{ 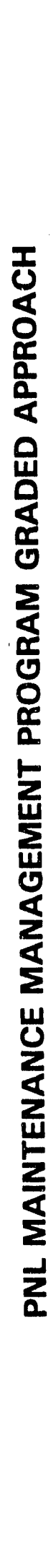 } & 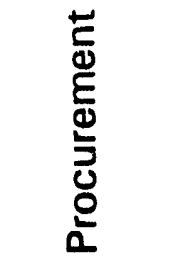 & 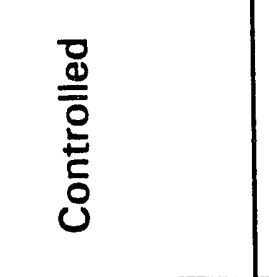 & 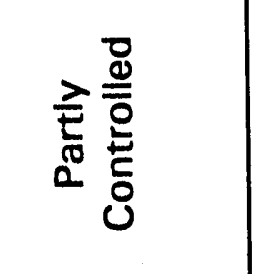 & $\begin{array}{l}\frac{4}{0} \\
\frac{c}{\omega} \\
\frac{4}{0}\end{array}$ \\
\hline & 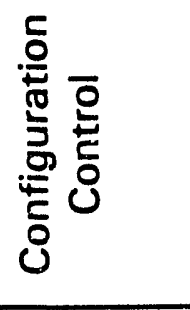 & $\frac{\text { Do }}{\overline{0}}$ & 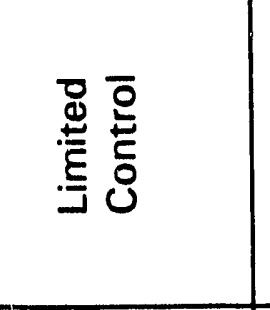 & $\stackrel{\mathscr{U}}{\mathbf{C}}$ \\
\hline & 茛 & 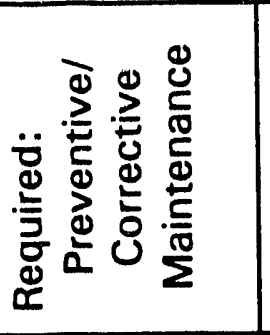 & 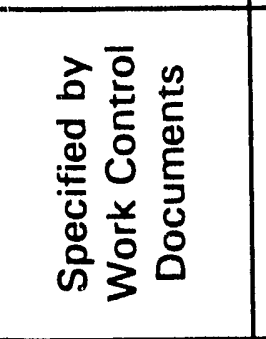 & 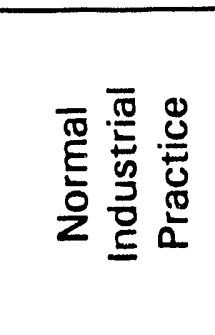 \\
\hline & 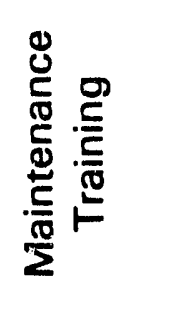 & 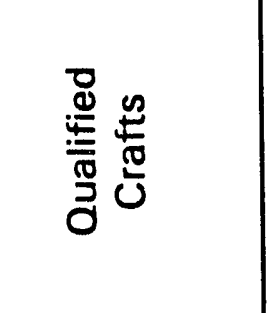 & 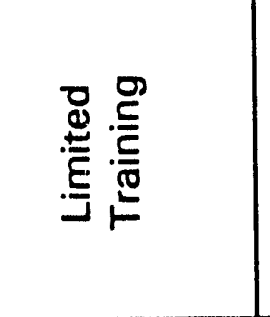 & 之 \\
\hline & 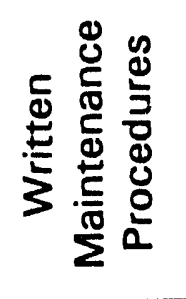 & 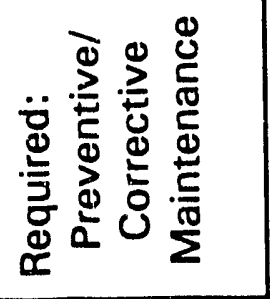 & 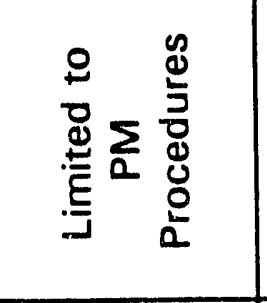 & 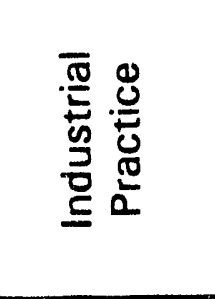 \\
\hline & 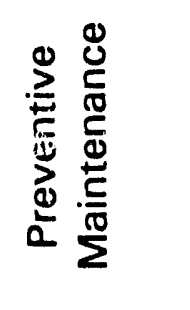 & 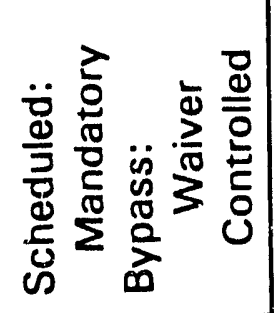 & 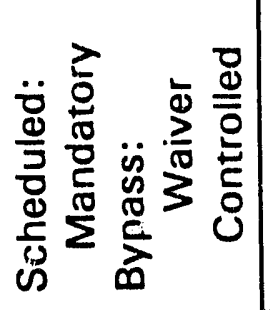 & 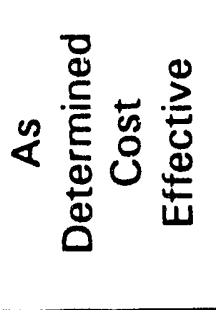 \\
\hline & 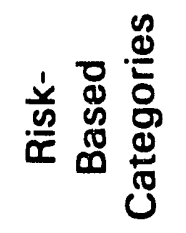 & $\frac{I}{\mathbb{I}} \frac{x}{\tilde{D}}$ & 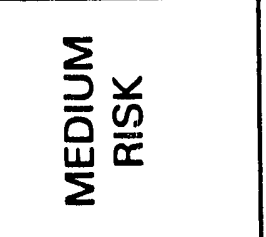 & $3 \frac{u}{0}$ \\
\hline
\end{tabular}




\section{DISTRIBUTION}

No. of

Copies

\section{OFFSITE}

2 DOE/Office of Scientific and Technical Information

\section{ONSITE}

6
DOE Richland Field office
J. J. Sutey (4)
J. D. Davidson
B. E. Hill

Westinghouse Hanford Company E. L. Fisk

\section{Pacific Northwest Laboratory}

J. D. Bright (10), P7-08

T. D. Chikalla, P7-75

J. C. Dunn, P8-20

L. R. Eberhardt, $P 7-70$

A. M. Fillion, P7-78

P. J. Gaither, P7-25

D. P. Higby, P7-78

G. R. Hoenes, P7-78

L. V. Kimme1, P7-70

R. R. King, P7-70

D. E. Knowition, P7-40

L. E. Maples, P7-39

C. L. Nelson, P8-20

R. V. Richardson, P7-63

B. D. Robertson, P8-01

R. S. Spencer, P7-65

J. W. Wald, K2-22

M. A. Williams, P7-60

P. A. Wright, P7-78 Publishing Coordination Technical Report Files (5) 


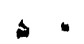
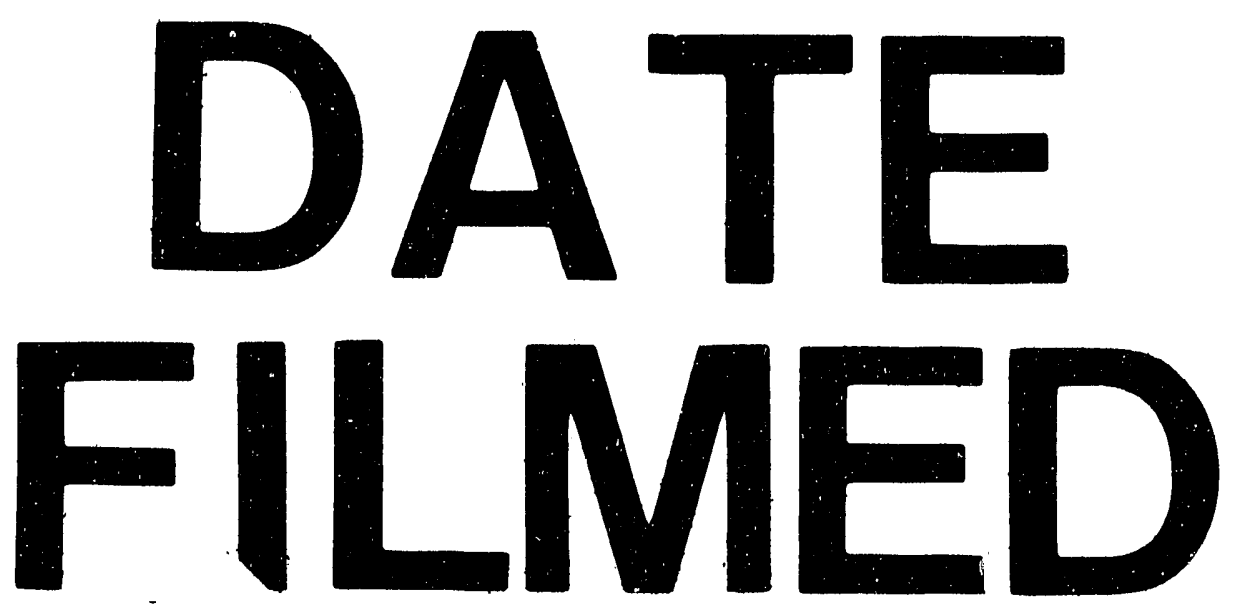

高

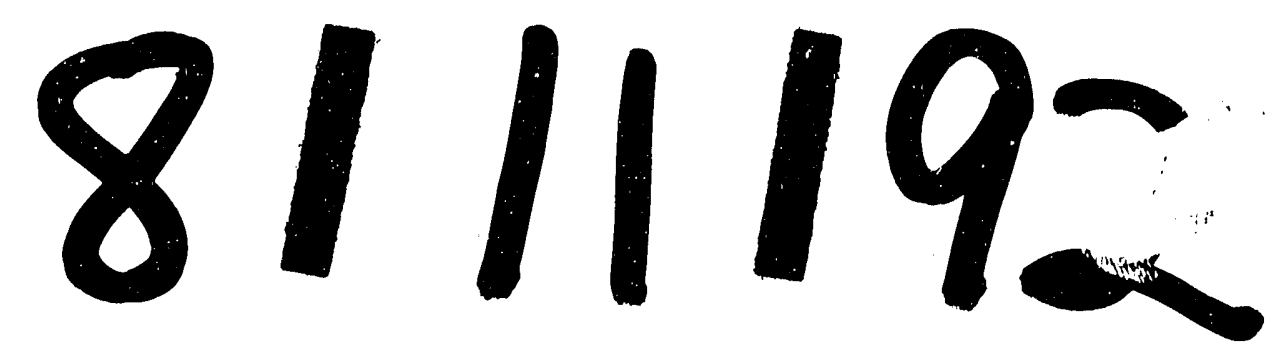


